\title{
EFEKTIVITAS SECANT PILE DENGAN MENGGUNAKAN BANTUAN BAMBU, CRUSHED STONE, KAYU, PASANGAN BATA, DAN MORTAR
}

\author{
Jason $^{1}$ dan Alfred Jonathan Susilo \\ ${ }^{1}$ Program Studi Sarjana Teknik Sipil, Universitas Tarumanagara, Jl. Letjen S. Parman No.1 Jakarta \\ jason.325160085@stu.untar.ac.id \\ ${ }^{2}$ Program Studi Sarjana Teknik Sipil, Universitas Tarumanagara, Jl. Letjen S. Parman No.1 Jakarta \\ alfredsusilo@gmail.com
}

Masuk: 2-07-2020, revisi: 19-07-2020, diterima untuk diterbitkan: 04-08-2020

\begin{abstract}
Nowdays, infrastructure process in Indonesia is growing rapidly. One of these problems is lack of lands so basement is the best solution to chose with. The main problem in basement construction that often encountered is the high rise construction around it so that it will required a retaining wall structure that can maintan the stability of the soil due to the force on the surface. The retaining wall is one of the most important elements in construction work, which can affect the overall construction work. This element serve to withstand lateral soil pressure caused by buried soil or unstable native soil. Basically, a retaining wall is a construction element that has been used for many years. To solve this problem, secant pile is used. This research that will be conducted is to use river stone in secant pile which will become another alternative for casting bentonite in the second stage of secant pile work. In this study, we will compare the effectiveness of secant pile by using the aid of bamboo, crushed stone, woods, bricks, and mortar.
\end{abstract}

Keywords: secant pile; bamboo; crushed stone; woods; mortar

\begin{abstract}
ABSTRAK
Saat ini, proses perkembangan infrastruktur di Indonesia berkembang dengan pesat. Salah satu permasalahan yang ada adalah terbatasnya ketersediaan lahan sehingga basement menjadi solusi yang banyak dipilih. Masalah utama dalam pembangunan basement yang sering dihadapi adalah adanya pembangunan tinggi di sekitarnya sehingga dibutuhkan struktur dinding penahan tanah yang dapat menjaga kestabilan tanah akibat beban yang ada di permukaan. Dinding penahan tanah merupakan salah satu elemen penting dalam pekerjaan konstruksi yang paling dasar, yang dapat mempengaruhi pekerjaan konstruksi secara keseluruhan. Elemen ini berfungsi untuk menahan tekanan tanah lateral yang ditimbulkan tanah urug ataupun tanah asli yang labil. Pada dasarnya, dinding penahan tanah merupakan elemen konstruksi yang sudah digunakan sejak bertahun-tahun lalu. Untuk mengatasi masalah tersebut, maka digunakan secant pile. Penelitian yang akan dilakukan adalah menggunakan batu kali, kayu, bambu pada secant pile yang akan menjadi alternatif lain cor-an bentonite pada tahap kedua pelaksanaan pekerjaan secant pile. Pada penelitian ini juga akan membandingkan efektifitas secant pile dengan menggunakan bantuan bambu, crushed stone, kayu, pasangan bata, dan mortar.
\end{abstract}

Kata kunci: secant pile; bambu; crushed stone; kayu; mortar

\section{PENDAHULUAN}

Perkembangan teknologi yang telah memberikan dampak yang besar dalam setiap bidang ilmu, salah satunya adalah bidang teknik sipil. Perencanaan suatu bangunan harus dilakukan dengan baik dan matang. Terbatasnya lahan sering kali menjadi suatu kendala, maka efisiensi yang dapat dilakukan adalah dengan membuat ruang bawah tanah (basement) untuk tempat parkir ataupun digunakan fungsi lainnya. Selain itu, pada permukaan tanah juga terdapat komponen gravitasi yang menggerakan tanah ke bawah. Jika komponen gravitasi lebih besar dari geseran yang dihasilkan oleh tanah, maka akan terjadi longosoran pada tanah yang miring (Hardiyatmo, 2002).

Pada permukaan tanah miring itu, disebut dengan analisis stabilitas lereng. Analisis itu sering dijumpai pada perancangan - perancangan bangunan. Umumnya analisis itu dipakai/digunakan untuk mengecek keamanan dari lereng alam, lereng urungan tanah, dan lereng galian. Penyebab kelongsoran lereng terdiri dari dua hal yaitu akibat pengaruh luar (external effect) dan pengaruh dari dalam (internal effect) (Hardiyatmo, 2002). 
Pengaruh kelongsoran dari luar ini adalah pengaruh yang menyebabkan bertambahnya perubahan kuat geser dari tanahnya, seperti salah satu contohnya adalah perbuatan manusia yang mempertajam kemiringan tebing. Kemudian untuk pengaruh dari dalam adalah tidak adanya perubahan kondisi luar atau gempa bumi untuk longsoran yang terjadi. Contohnya adalah tekanan air pori di dalam lerengnya bertambah. Dapat dilakukan banyak metode untuk melakukan pencegahan terhadap longosran yang terjadi, salah satunya adalah pembuatan Dinding Penahan Tanah (Retaining Wall).

Retaining Wall adalah dinding penahan tanah dimana pekerjaan konstruksinya juga merupakan salah satu yang pekerjaan yang penting dalam suatu proyek karena dapat mempengaruhi hasil akhir dari proyek tersebut. Oleh karena itu, perencanaan dan perhitungan harus disiapkan dengan matang. Pada hal ini, analisis yang lebih dalam sangat diperlukan karena ada beberapa faktor yang mungkin berpengaruh di dalamnya seperti perbedaan muka air, model tanah, dan lainnya. Dinding penahan tanah yang digunakan adalah Secant Pile (Hardiyatmo, 2014).

Secant pile digunakan untuk mencegah tanah atau material lainnya agar tidak runtuh atau longsor. Selain itu, berguna untuk menjaga daya dukung dan kestabilan tanah. Untuk memperkuat kestabilan tanah dan memperkokoh, secant pile dapat dilakukan pengangkuran. Agar daya dukung dapat akurat, diperlukan juga penyelidikan tanah yang pasti dan akurat. Terdapat dua metode yang bisa kita gunakan untuk menentukan kapasitas bored pile, metode statis dan dinamis.

Metode statis dalam penyeledikan tanah adalah standard penetrasi tes (SPT) dan sondir. Pelaksanaan sondir ini berguna untuk mengetahui hambatan lekat tanah dan perlawanan penetrasi konus yang merupakan indikasi dari kekuatan daya dukung lapis tanah dengan menggunakan rumus empiris. Pelaksanaan Standard Penetrasi Test (SPT) berguna untuk mendapatkan gambaran lapisan tanah berdasarkan warna dan jenis tanah melalui pengamatan secara visual.

Perencanaan DPT (Dinding Penahan Tanah) mencakup berbagai kegiatan yang dilakukan dengan berbagai tahapan yang meliputi, perencanaan teknis dan kelayakan studi. Dua hal itu dilakukan agar menjamin hasil akhir dari suatu konstruksi yang aman, kuat, dan juga ekonomis. Dinding penahan tanah bisa dibilang aman, jika telah diperhitungkan faktor keamanannya baik dalam segi pergeseran, guling, dan penurunan daya dukung tanah. Selain hal-hal tersebut, analisis stabilitas juga merupakan salah satu aspek yang tidak bisa atau boleh diabaikan karena sangat mempengaruhi dalam segi usia desain dinding penahan itu sendiri.

\section{METODE PENELITIAN}

\section{Pengumpulan data}

Pada penelitian ini, data tanah yang digunakan berlokasi di Kembangan dan Tanjung Priuk, Jakarta Barat dan Jakarta Utara. Data tanah yang dikumpulkan berupa boring log dan hasil tes laboratorium. Data tanah tersebut berupa N-SPT yang kemudian dilakukan korelasi untuk mendapatkan beberapa parameter tanah lainnya yang diperlukan untuk analisis.

\section{Pengolahan data}

Studi literatur perlu dilakukan terlebih dahulu sebelum melakukan pengolahan data. Tujuan studi literatur dilakukan untuk memahami dasar-dasar teori yang perlu diperhatikan dan rumus-rumus yang akan digunakan untuk analisis seperti pada Gambar 1. Setelah melakukan studi literatur kemudian dilanjutkan dengan pengolahan data-data tanah dan material yang telah dikumpulkan. Hasil analisis defleksi secant pile hanya dilakukan secara perhitungan manual. Setelah mengetahui besarnya defleksi untuk masing-masing bantuan bahan pengganti secant pile, maka hasil tersebut akan dibandingkan dan membuat kesimpulan dan saran. 


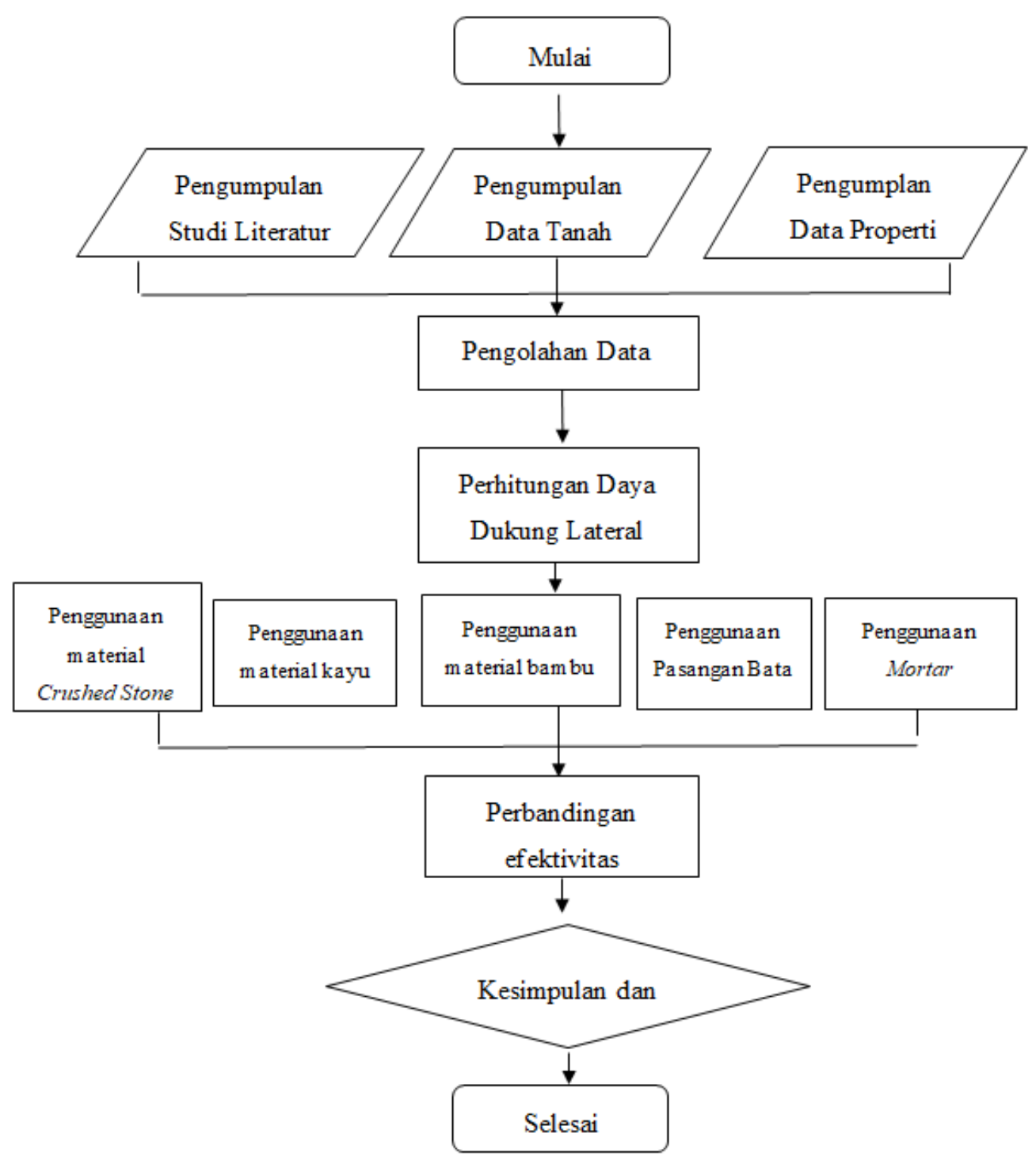

Gambar 1. Diagram alir penelitian

\section{HASIL DAN PEMBAHASAN}

\section{Analisi kedalaman secant pile}

Pada bagian ini, akan dilakukan perhitungan kedalaman secant pile berdasarkan $\sum \mathrm{M}=0$, yaitu $\sum \mathrm{M}=-7.068 \mathrm{~d}^{2}+$ $57.574 \mathrm{~d}-235.918=0$, dan diperoleh $\mathrm{d}=8.17 \mathrm{~m}$. Akan dilakukan pembuatan basement 3 lantai dengan masingmasing kedalaman $3.2 \mathrm{~m}$ dan dengan direncakannnya nilai Safety Factor $(\mathrm{SF})=1.3$, maka kedalaman penanaman secant pile $=8.17 \times 1.3=10.62 \mathrm{~m}$. Jadi panjang total secant pile $(\mathrm{H})$ adalah kedalaman galian + kedalaman penanaman $=9.6+10.62=20.22 \mathrm{~m} \approx 21 \mathrm{~m}$. 
Efektivitas Dinding Penahan Tanah Tipe Secant Pile Jason, et al. dengan Menggunakan Bantuan Bambu, Crushed Stone, Kayu, Pasangan Bata, dan Mortar

\section{Analisis defleksi secant pile terhadap bahan bantuan}

Pada bagian ini, akan digambarkan sketsa gambar bahan bantuan secant pile seperti pada Gambar 2, Gambar 3, Gambar 4, Gambar 5, dan Gambar 6.

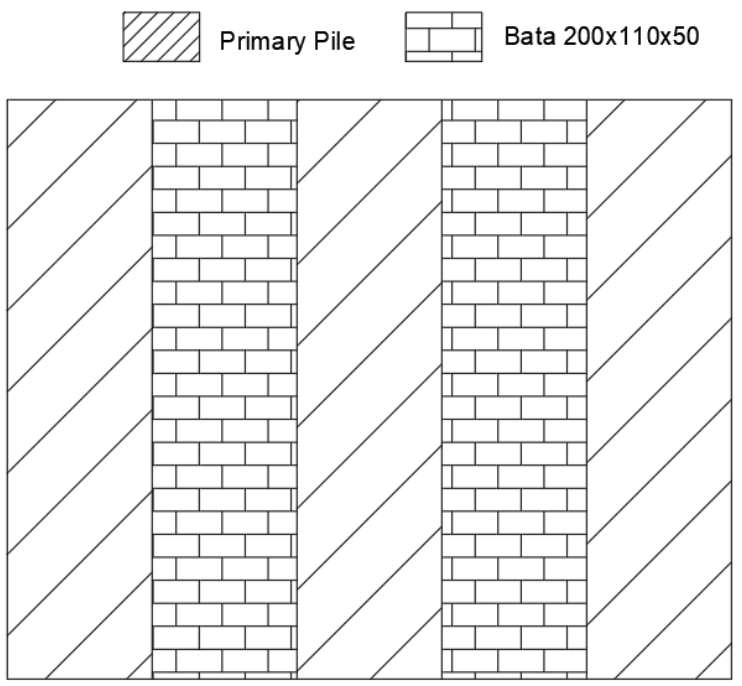

Gambar 2. Tampak depan secant pile dengan bantuan bata merah

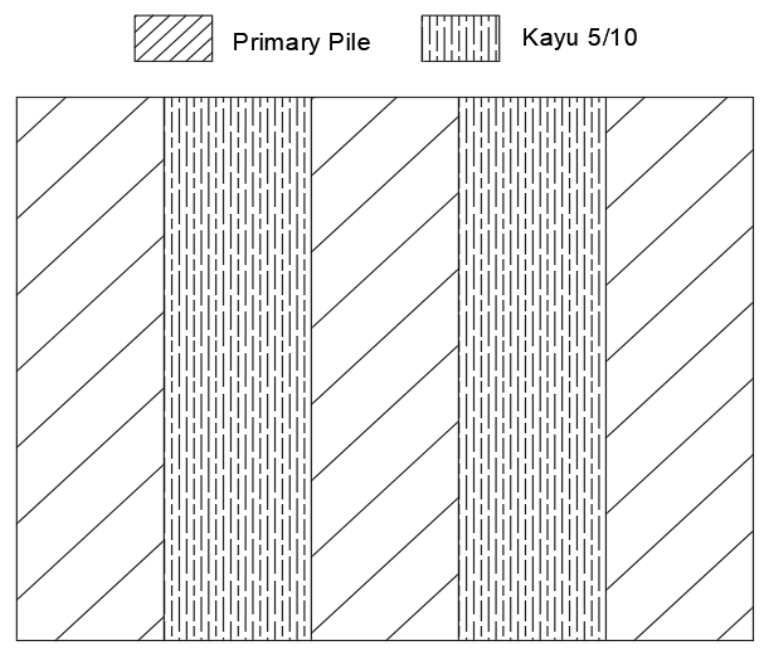

Gambar 3. Tampak depan secant pile dengan bantuan kayu 


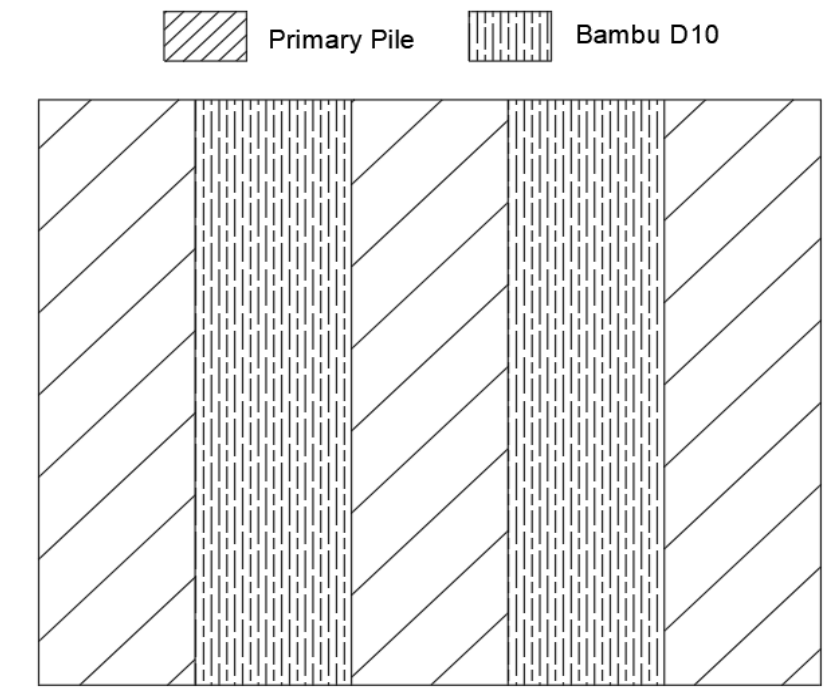

Gambar 4. Tampak depan secant pile dengan bantuan bambu

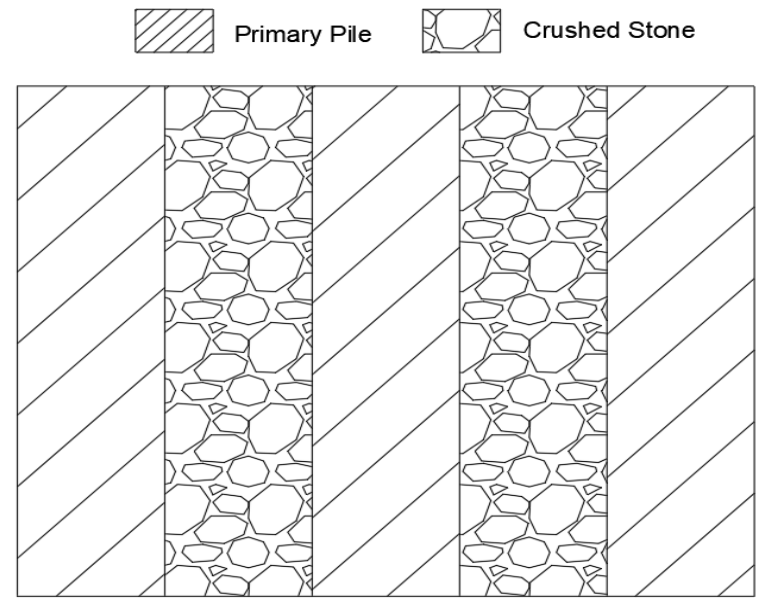

Gambar 5. Tampak depan secant pile dengan bantuan crushed stone

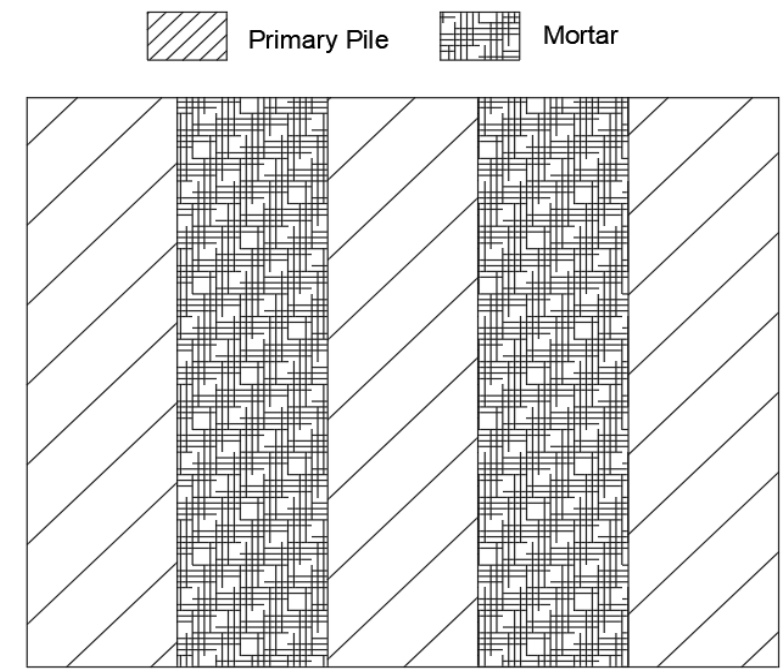

Gambar 6. Tampak depan secant pile bantuan mortar 
Efektivitas Dinding Penahan Tanah Tipe Secant Pile Jason, et al. dengan Menggunakan Bantuan Bambu, Crushed Stone, Kayu, Pasangan Bata, dan Mortar

Tabel 1. Hasil pengecekan defleksi secant pile terhadap bahan bantuan

\begin{tabular}{cccc}
\hline Bahan Bantuan & $\begin{array}{c}\text { Deflesi Lateral } \\
(\mathrm{mm})\end{array}$ & $\begin{array}{c}\text { Defleksi Lateral Ijin } \\
\text { SNI 8460:2017 }(\mathrm{mm})\end{array}$ & Keterangan \\
\hline Bata Merah & 40,47 & 25 & TIDAK OK \\
Kayu & 40,52 & 25 & TIDAK OK \\
Bambu & 40,52 & 25 & TIDAK OK \\
Crushed Stone & 40,51 & 25 & TIDAK OK \\
Shot Crete & 20,26 & 25 & OK \\
\hline
\end{tabular}

\section{Analisis kegagalan dinding penahan tanah penggalian}

Pada bagian ini, akan digambarkan sketsa gambar analisis kegagalan dinding penahan tanah penggalian seperti pada Gambar 7, Gambar 8, Gambar 9, dan Tabel 2.

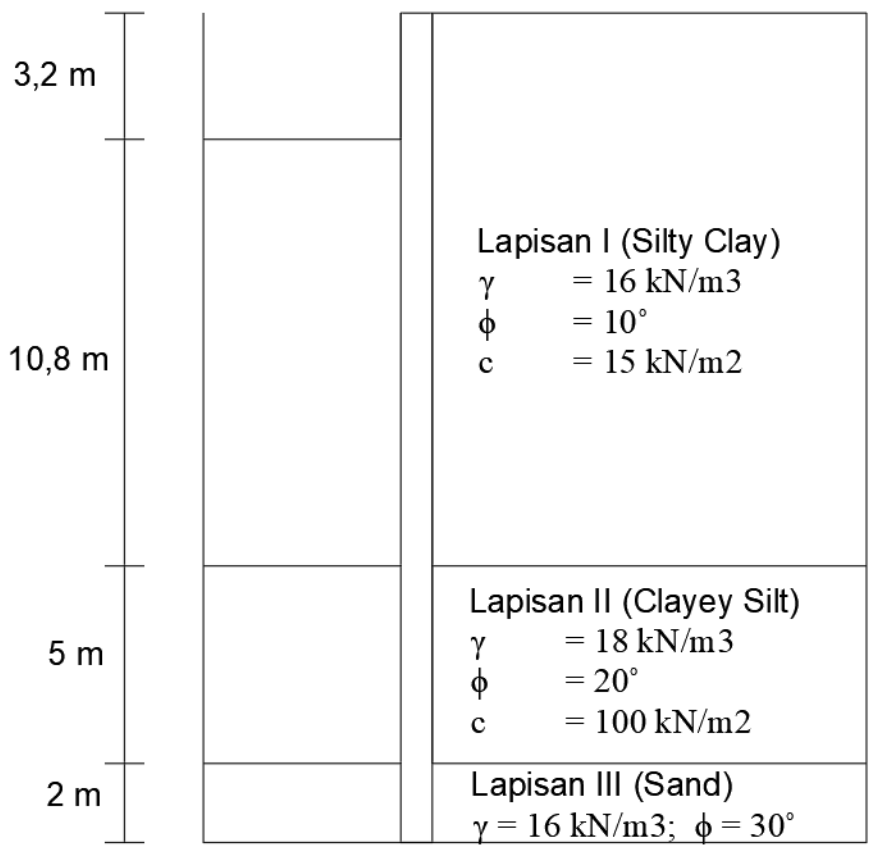

Gambar 7. Kondisi setelah penggalian 3,2 m 


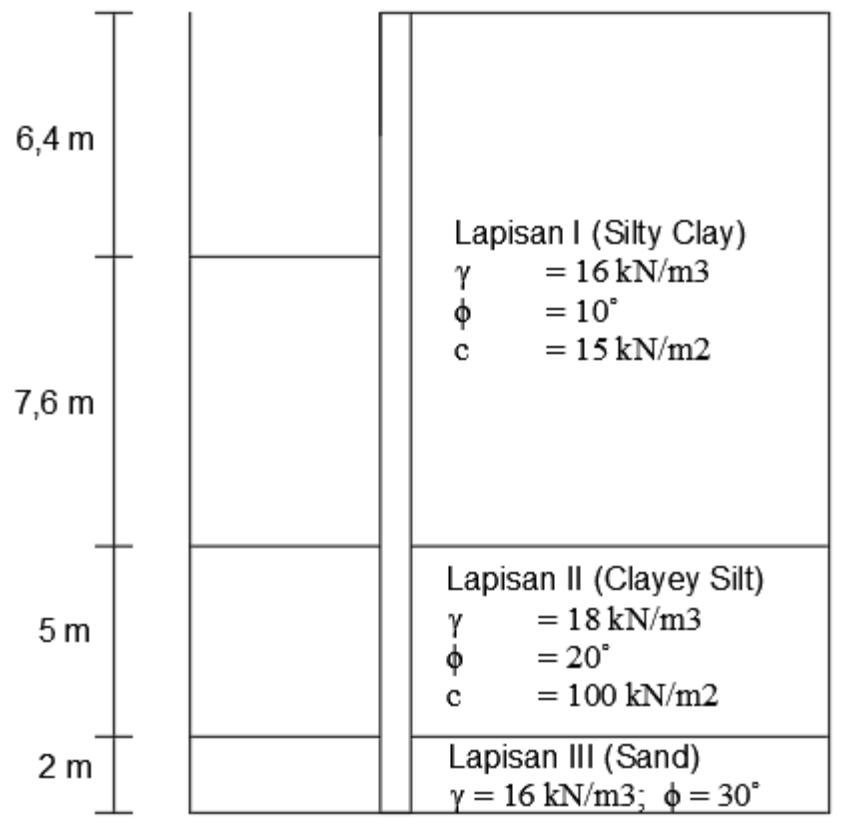

Gambar 8. Kondisi setelah penggalian 6,4 m

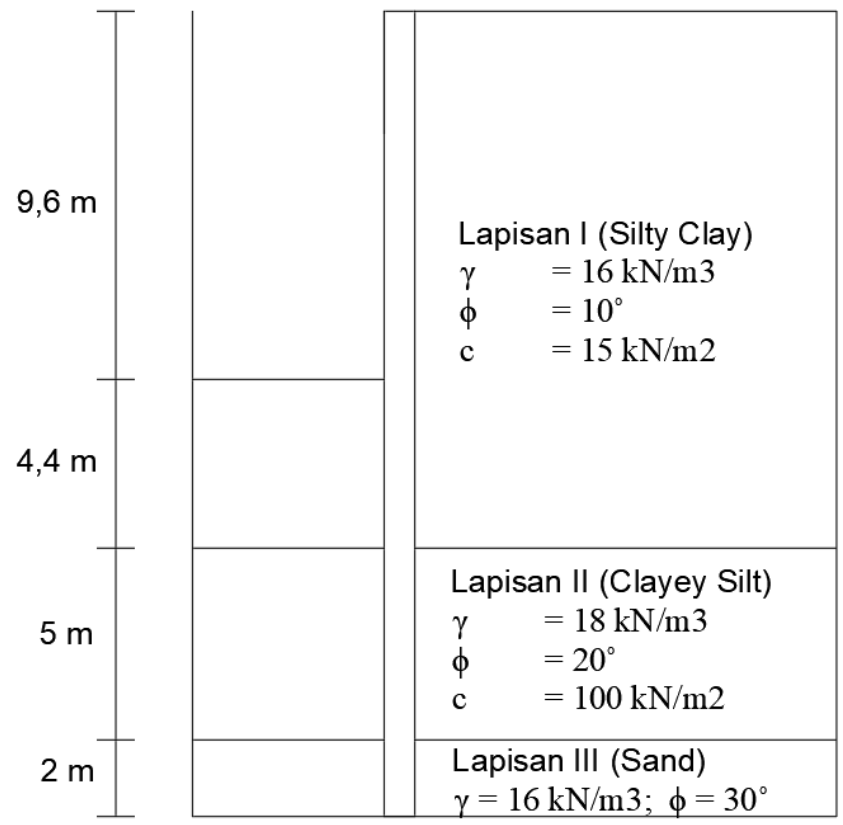

Gambar 9. Kondisi setelah penggalian 9,6 m

Tabel 2. Hasil pengecekan dinding penahan tanah terhadap galian

\begin{tabular}{ccccc}
\hline $\begin{array}{c}\text { Kedalaman } \\
\text { Galian }(\mathrm{m})\end{array}$ & $\begin{array}{c}\text { Faktor } \\
\text { Keamanan } \\
\text { Geser }\end{array}$ & $\begin{array}{c}\text { Faktor } \\
\text { Keamanan } \\
\text { Guling }\end{array}$ & Pengecekan Geser & Pengecekan Guling \\
\hline 3,2 & 3,1748 & 2,1956 & OK & OK \\
6,4 & 2,4861 & 1,3942 & OK & TIDAK OK \\
9,6 & 1,9271 & 0,8661 & TIDAK OK & TIDAK OK \\
\hline
\end{tabular}




\section{KESIMPULAN DAN SARAN}

\section{Kesimpulan}

Berdasarkan hasil analisis defleksi lateral yang terjadi pada secant pile dengan menggunakan bahan bantuan, hanya Mortar dengan tipe Shot Crete yang aman terhadap defleksi lateral. Sedangkan, untuk pengecekan kegagalan Secant Pile terhadap kedalaman galian didapat bahwa pada kedalaman 6,4 m tidak aman terhadap guling dan pada kedalaman 9,6 sudah tidak aman untuk geser dan guling.

\section{Saran}

Saran bagi penelitian selanjutnya agar mempersiapkan data tanah yang lebih lengkap supaya memberikan datadata yang lebih akurat dalam melakukan analisis perhitungan. Dalam melakukan perhitungan analisis mungkin dapat dibantu oleh program untuk keakurataan yang lebih pasti. Selain itu, untuk jarak antar primary pile bisa diatur lebih dekat jaraknya supaya defleksi yang terjadi kemungkinan besar bisa lebih kecil.

\section{DAFTAR PUSTAKA}

Hardiyatmo, H.C. Teknik Pondasi I, Yogyakarta: Beta Offset, 2002.

Hardiyatmo, H.C. Analisa dan Perencanaan Fondasi 1. Yogyakarta, 2014.

Badan Standardisasi Nasional. SNI 8460:2017. Persyaratan Perancangan Geoteknik. Badan Standardisasi Nasional. Jakarta, 2017 